\title{
ANALYSIS ON THE AREA CHANGES AND ITS INFLUENCING FACTORS OF THE LAKES IN WUHAN CITY BASED ON GOOGLE EARTH ENGINE
}

\author{
Tiantian Gong ${ }^{1,2}$, Shuangyu Xie ${ }^{1,2 *}$, Haonan Zhao ${ }^{3}$ \\ ${ }^{1}$ Hubei Provincial Key Laboratory of Geographical Process Analysis \& Simulation, Wuhan 430079, China \\ 2 The College of Urban \& Environmental Science, Central China Normal University, Wuhan 430079, Hubei, China - \\ (wzsgtt111@163.com, xieshuangyu@mail.ccnu.edu.cn) \\ ${ }^{3}$ College of Surveying and Geo-Informatics, Tongji University, 1239 Siping Road, Shanghai, China - 1931986@tongji.edu.cn
}

Commission TCIII, WG III/6

KEY WORDS: Google Earth Engine, Wuhan City, Urban Lakes, Dynamic Monitoring, Long Time Series, Landsat

\begin{abstract}
:
Urban lakes play an important role in urban development and environmental protection, and lakes are an important city card of Wuhan city. We calculated the lake area of in Wuhan city from 1987 to 2019 and its change over time and in space by using the MNDWI method and the Google Earth Engine (GEE) platform, and explored the driving force of lake area changes by using Pearson correlation coefficient in this paper. The results show: (1) The lakes in Wuhan city were shrinking and the total area decreased from $837.89 \mathrm{~km}^{2}$ in 1987 to $734.10 \mathrm{~km}^{2}$ in 2019 at a rate of $3.15 \mathrm{~km}^{2}$ per year, but changed differently in different stages: increasing in the period of 1987 to1993, decreasing in the period of 1993 to 2004 while being stable in the period of 2004 to 2019. (2) The lakes were mainly distributed in the central and eastern parts of Wuhan city (i.e., Wuchang District, Jiangxia District, and Caidian District). (3) Climate factors and human activities have jointly affected the changes in lake area. In terms of climate factors, the total area of lakes had a strong correlation with precipitation and temperature. In terms of human activities, permanent population had a moderate correlation with the lake changes. The study verified the feasibility of monitoring the long-term lake sequence on the GEE platform, and provided reference for lake protection in Wuhan city.
\end{abstract}

\section{INTRODUCTION}

Urban lakes are an important part of urban wetland ecosystem, with functions such as climate regulation, urban water sources, flood control and water storage (Xie et al., 2018; Cuffney et al., 2010). In the context of rapid population growth and accelerated urbanization, the demand and use of companies around the lake and urban population for water resource are constantly increasing. The number and area of urban lakes have being greatly reducing, which has a serious impact on climate change, economic development and human activities (Zhang et al., 2015; Yang et al., 2015; Chen et al., 2015). Lakes are an important card of Wuhan city. Wuhan city has been selected as one of the three major water cities in the world's inland megacities, and is the 'city of hundreds of lakes'. However, the area of lakes in Wuhan city has decreased dramatically (Deng et al., 2017), causing a series of environmental and ecological problems, such as waterlogging and unsustainable development of the city. In addition, due to the impact of the construction of some major projects such as the Three Gorges Dam, the groundwater level has dropped significantly, which is a serious challenge for the protection of lakes. Wuhan city have enacted lake protection regulations to curb the decline of lakes since 2000 (Liu et al., 2007; Du et al., 2010). It is extremely important to study the long-term temporal and spatial changes of the lakes since it has great strategic significance for improving the ecological environment and the sustainable development of Wuhan city.

Remote sensing technology, characterised as wide detection range, periodic data acquisition and fast data acquisition, has great advantages in temporal and spatial resolution (Yasir et al.,
2020). It provides a means for monitoring the long time series of lakes (Qiao et al. 2019a; Zhang et al., 2014). At present, many scholars have studied lake changes, mainly focusing on the following three aspects. (1) Study on the changes of a typical single lake, for example, to quantify the area changes of Qinghai Lake, a satellite-based survey based on Landsat images from the 1980 s to 2010 s has been performed by Tang et al. (2018). Zhang et al. (2011) used Landsat, CBERS and HJ-1A/1B satellite data to explore the changes of Nam Co lake. Cao et al. (2021) used Landsat images from 1973 to 2019 to obtain a 46-year area dataset for the Hongjiannao Lake. (2) Study on the spatial pattern of lake changes in large-scale regions, including cities, provinces, and metropolitan regions. For example, Qiao et al. (2019b) estimated 315 lakes on the Tibetan Plateau, and the results showed that the expansion of lakes was mainly concentrated in the central and northern parts of the Tibetan Plateau. Ma et al. (2017) studied the long time series of the lake area from 1973 to 2015 in Wuhan city and found that the area of lakes in central districts of Wuhan began to decrease drastically after 1996. (3) The driving forces of lake changes. Both climate factors and human activities have been explored by mainly using correlation analysis of lake changes (area, lake level, water volume) and influencing factors. Song et al. (2015) analyzed the driving force of dramatic changes of Namco lake level, such as precipitation, annual mean air temperature, potential evaporation and mean relative humidity. Zhang et al. (2020) used the temperature and precipitation from 95 China Meteorological Administration stations to analyze Tibetan Plateau's lake volume changes during the period of 2003-2018.

\footnotetext{
* Corresponding author
} 
For monitoring the long time series of lake changes, scholars often use traditional remote sensing methods, which are difficult to acquire and process large amounts of remote sensing images. In recent years, the GEE has changed the traditional remote sensing method and provided a new means for rapidly processing remote sensing data (Pekel et al., 2019; Jiang et al., 2021; Zhou et al., 2019). For example, Deng et al. (2019) processed 75593 scenes of Landsat images to investigate changes of open-surface water bodies in the Yangtze river based on the GEE platform. Therefore, we use the modified normalized difference water index (MNDWI) method (Xu., 2006) and the GEE platform to calculate the lake area from 1987 to 2019 and its change over time and in space, and explore the influencing factors of lake changes. The study verified the feasibility of monitoring the longterm lake sequence on the GEE platform, and provided reference for lake protection in Wuhan city.

\section{DATA AND METHOD}

\subsection{Study Area}

Wuhan city is located in the middle reaches of the Yangtze River and the east of the Jianghan Plain. The terrain of Wuhan city is flat and is dominated by flood plains. The climate belongs to the subtropical monsoon climate, with abundant rainfall throughout the year. The precipitation is concentrated in June to August, accounting for about $40 \%$ of the annual rainfall. Wuhan city is nicknamed water city, because the Yangtze River and Han River flow through Wuhan city, and Wuhan city includes hundreds of lakes, including Yanxi Lake, Nanhu Lake, East Lake, and Tangxun Lake. The water area accounts for about $25 \%$ of the city's area. Wuhan city is the largest city and the only subprovincial city in central China. It has 13 administrative regions, such as Jiang'an District, Huangpi District, Hongshan District, and Dongxihu District. We selected the entire jurisdiction of Wuhan city as the research area (Figure 1).

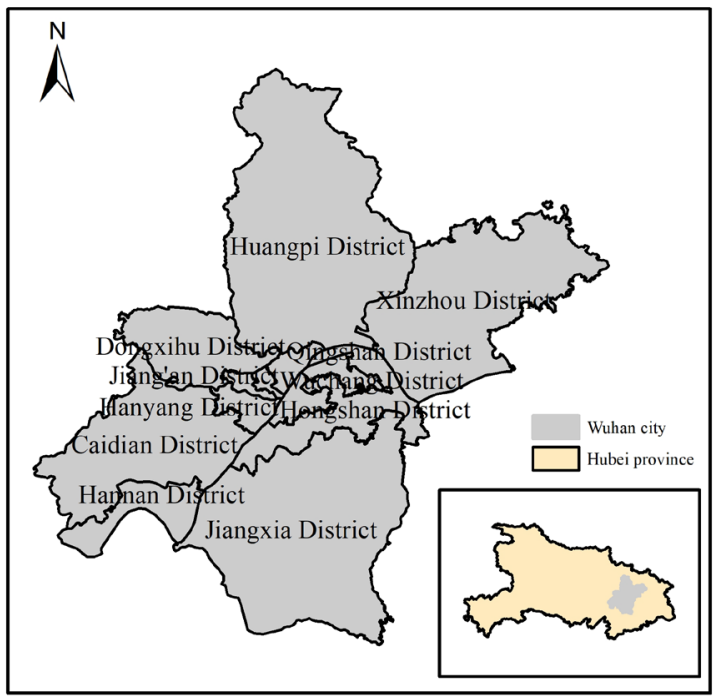

Figure 1. The location of the study area.

\subsection{Data}

2.2.1 Landsat time series: The Landsat series of satellites was launched in 1972 and was jointly managed by NASA and the United States Geological Survey (USGS). It is the longestrunning Earth observation program. We used Landsat 4-5 before 2012 and Landsat-8 OLI data after 2013. Based on the GEE platform, Landsat Surface Reflectance Tier 1 dataset is selected as the data set., which is the atmospherically corrected surface reflectance. In addition, we selected Landsat images with low cloud cover to ensure image quality. In order to reduce the impact of precipitation and seasonal changes, we selected remote sensing images from September to December.

2.2.2 Meteorological and socioeconomic data: The meteorological data from 1987 to 2020 of Wuhan Meteorological Stations was obtained from China Meteorological Data Network (http://data.cma.cn/en). The dataset included temperature, precipitation, and relative humidity. The socioeconomic data, such as population, GDP and other data was obtained from Wuhan Statistical Yearbook.

\subsection{Method}

2.3.1 Lake vector extraction based on GEE platform: The data processing in this paper includes image preprocessing, lake vector extraction and accuracy verification. Image preprocessing and lake vector extraction are processed based on the GEE platform, and the accuracy verification is completed in ArcGIS. The six specific steps are as follows: (1) to screen Landsat 5 and 8 series of images from September to December of 1984-2020 based on the Landsat Surface Reflectance Tier 1 dataset; (2) to use the cloud removal algorithm to retain the pixels with cloudiness less than $20 \%$; (3) to take the median value of each year's image collection for image fusion, and to crop it according to Wuhan city vector boundary (Figure 2); (4) to use the MNDWI method to extract water bodies (Xu, 2006; Chen et al., 2017), which can reduce the impact of urban buildings; (5) to choose an appropriate threshold to realize image binarization and convert it to vector; (6) to export the fusion images of Wuhan city every year and the vector files based on the MNDWI method. After extracting the lake vector based on the GEE platform, visual interpretation was performed in ArcGIS to preserve the reservoir and lake water bodies.

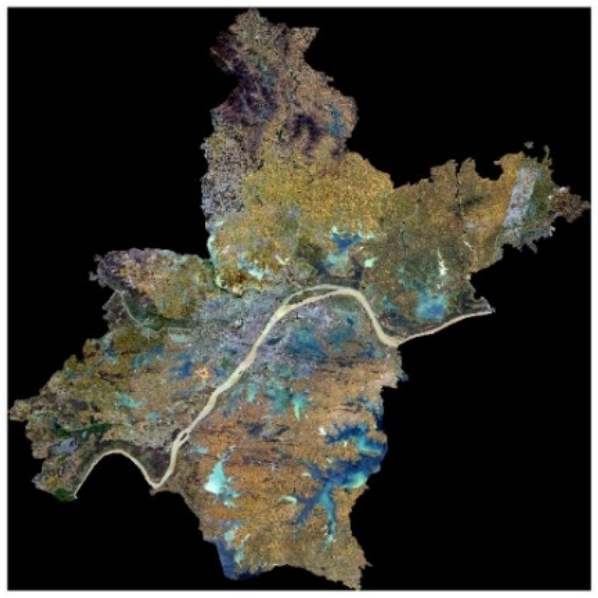

Figure 2. Schematic diagram of fusion image (1992).

2.3.2 Lake change intensity index: Lake change intensity index (LCII) represents the relative degree of the change in the area of a single lake or a region in a certain period ( $\mathrm{Wu}$ et al., 2019), and is calculated as follows:

$$
C=\frac{A_{1}-A_{0}}{A_{0} * \Delta t} * 100
$$

where $A_{0}=$ lake area at the beginning of the study period 
$A_{1}=$ lake area at the end of the study period

$\Delta t=$ study interval

2.3.3 Attribution analysis: We analyzed the correlation between the lake area and climatic factors and human factors in Wuhan city, and then explored the driving force of lake changes. The Pearson correlation coefficient is used to measure the linear correlation between two variables. It represents the quotient of the covariance and standard deviation between two variables. The formula is as follows:

$$
r=\frac{\sum X Y-\frac{\sum X \sum Y}{N}}{\sqrt{\left(\sum X^{2}-\frac{\left(\sum X^{2}\right)}{N}\right)\left(\sum Y^{2}-\frac{\left(\sum Y^{2}\right)}{N}\right)}}
$$

where $\quad r=$ the Pearson correlation coefficient

$X=$ lake area

$Y=$ climatic factors or human factors

$N=$ the number of samples

$r$ is between -1 and 1 . If the absolute value of $r$ is close to 1 , the correlation between variables is stronger. In other words, the greater the absolute value of the correlation coefficient between the lake area in Wuhan and a certain factor, the greater the impact of this factor on the change of lake area. The value range of $r$ is judged as follows: when $r$ is less than 0.2 , there is very weak correlation or no correlation; when $r$ is between 0.2 and 0.4 , there is a weak correlation; when $r$ is between 0.4 and 0.6 , there is a moderate correlation; When $\mathrm{r}$ is between $0.6-0.8$, there is a strong correlation; when $\mathrm{r}$ is between $0.8-1.0$, there is a very strong correlation.

\section{RESULTS AND DISCUSSION}

\subsection{Lake surface area change}

Figure 3 shows the distribution of lakes from 1987 to 2019 extracted from 18 remote sensing images by using abovementioned MNDWI method and Figure 4 shows the changes in lake areas in Wuhan city. As showed in Figure 4, in general, the lake areas in Wuhan city were shrinking. The total area decreased from $837.89 \mathrm{~km}^{2}$ in 1987 to $734.10 \mathrm{~km}^{2}$ in 2019 at a rate of 3.15 $\mathrm{km}^{2}$ per year, with a LCII of $-0.38 \%$. The changes in lake areas can be divided into three stages. Firstly, from 1987 to 1993, the total area of lakes in Wuhan city increased rapidly, with the LCII being $1.97 \%$, which was the most dramatic period of lake changes in the three stages. It is probably due to the implementation of the "returning farmland to lake" policy in Wuhan city from 1990 to 1993 . A large amount of farmland, cultivated land and other land were converted to lakes, which caused the total area of lakes to rise rapidly. Secondly, from 1993 to 2004, the total lake area decreased at an average rate of 16.17 $\mathrm{km}^{2}$ per year, basically same as that from 1987 to 1993 , but the LCII was $-1.70 \%$, lower than that of the previous stage. The situation was more complicated during the period of 1987-1993. The overall trend was downward, but the total area of lakes reached a peak again in 2002. Thirdly, after 2004, the total area of lakes was stable, with the LCII being only $-0.002 \%$, which is inseparable from the lake protection management and policies of Wuhan city.

From the spatial scale, lakes in Wuhan city were mainly distributed in the central and eastern parts of Wuhan city (i.e., Wuchang District, Jiangxia District, and Caidian District). There were some large lakes such as Tangxun Lake, Lu Lake and Liangzi Lake in Jiangxia District. Wuchang District had the famous East lake.

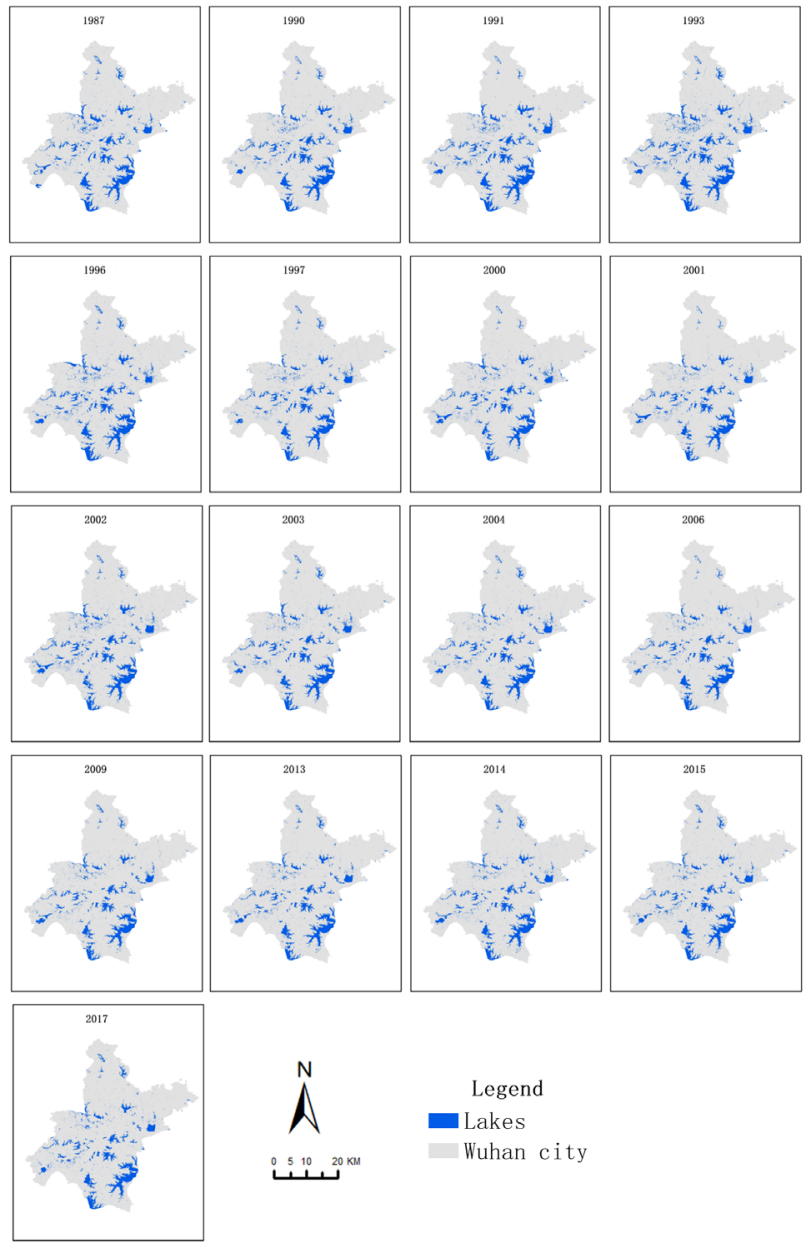

Figure 3. Distribution of lakes from 1987 to 2019.

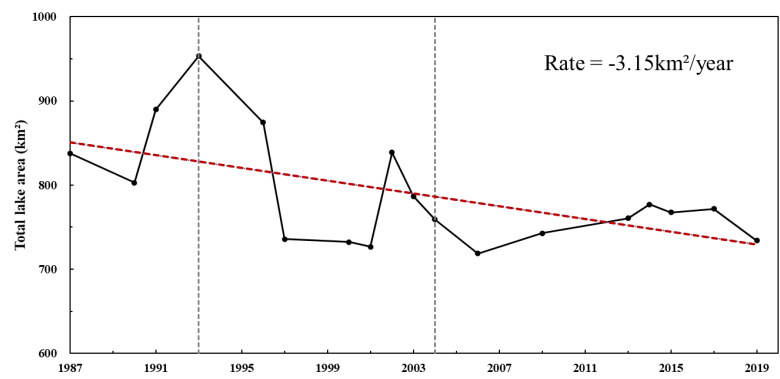

Figure 4. Changes in the area of lakes in Wuhan city.

\subsection{Lake changes associated with climate factors and human activities}

Climate factors and human activities have jointly affected the changes in lake area. Among climatic factors, precipitation and evaporation directly affect lakes, while temperature affects the transmission speed of water vapor flux, and indirectly affects lake changes. Since evaporation data cannot be obtained, three indicators of average temperature, precipitation, and relative humidity are finally selected. Social and economic data are often used to measure the intensity of human activities. The four indicators of population, Gross Domestic Product (GDP), the gross output value of agriculture, forestry, animal husbandry and fishery, and the area of arable land are selected. We used the Pearson correlation coefficient to analyze the correlation between the lake area and influencing factors. 
In terms of climate factors, the total area of lakes in Wuhan city had a strong correlation with precipitation and temperature, and a weak correlation with relative humidity (Figure 5). The precipitation in Wuhan City has shown a downward trend as a whole and the precipitation dropped from $120.78 \mathrm{~mm}$ to $87.78 \mathrm{~mm}$ with an average decline of $1 \mathrm{~mm}$ per year. It is divided into three stages: increasing period, decreasing period and stable period, which is very similar to the lake changes. The average temperature was negatively correlated with the lake changes. In the past 30 years, the average temperature has risen at a rate of $0.02^{\circ} \mathrm{C}$ per year. The increase in temperature will accelerate the transmission of water vapor flux and increase evaporation to a certain extent, resulting in the shrinkage of the lake. Relative humidity indicates the amount of water vapor in the air, and a humid climate is conducive to the expansion of lakes. The correlation coefficient between relative humidity and lake area changes was 0.37 (weak correlation). The relative humidity dropped rapidly before 2004, and the relative humidity rose again after 2004. The overall trend of relative humidity was decreasing. The lake area in Wuhan city reached the largest in 1993 when the temperature was the lowest $\left(16.22^{\circ} \mathrm{C}\right)$ and the precipitation was large $(132.05 \mathrm{~mm})$. In 2004 , the total lake area in Wuhan city was the smallest when the temperature was higher $\left(18.27^{\circ} \mathrm{C}\right)$ and the average humidity was the lowest $(69.58 \%)$. In summary, the lakes are sensitive to climate changes, and the impact of climate factors on the lake changes in Wuhan city is very significant.
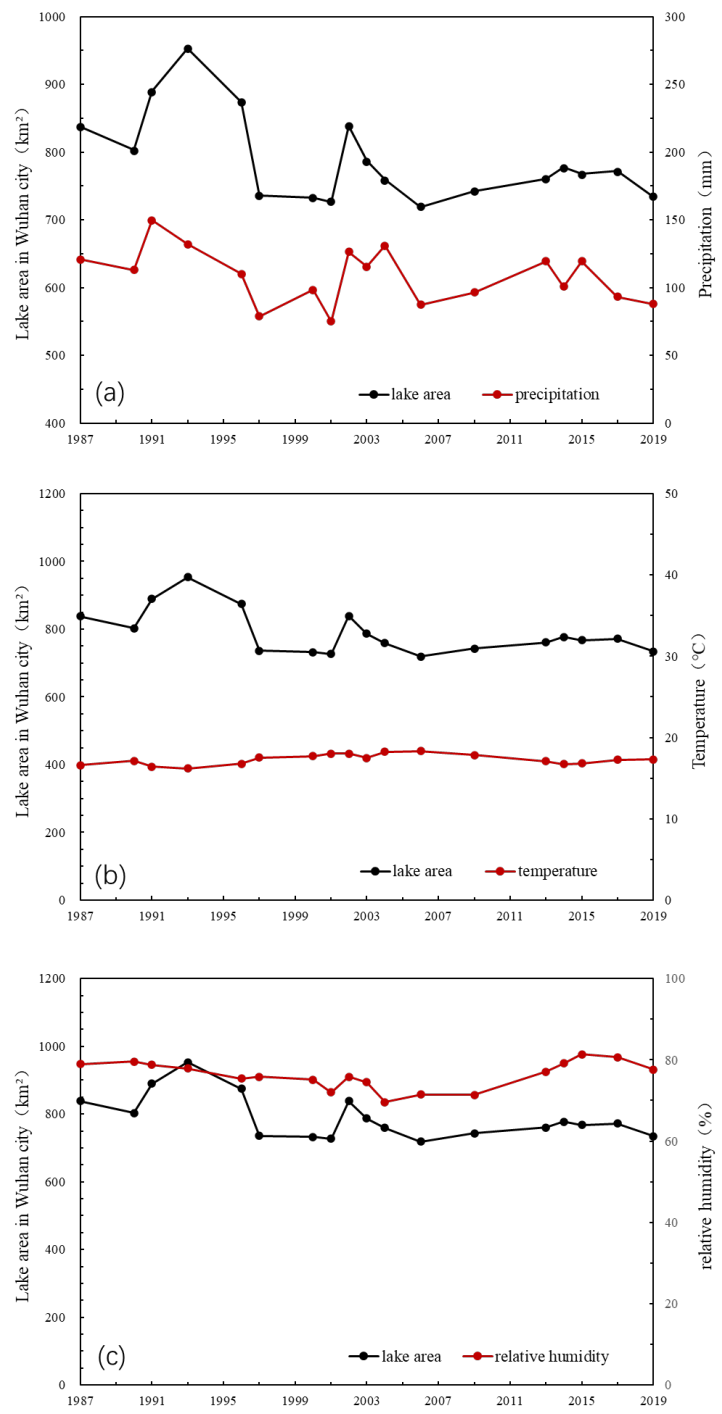

Figure 5. (a) Correlation between precipitation and lake area $(\mathrm{r}=0.73)$; (b) Correlation between temperature and lake area $(\mathrm{r}=-$ $0.70)$; (c) Correlation between relative humidity and lake area $(\mathrm{r}=0.37)$.

In terms of human activities, the four indicators had a certain correlation with the lake area changes in Wuhan city. Among them, permanent population had a moderate correlation with the lake changes $(r=-0.48)$, GDP and total agricultural output value were weakly correlated with lake changes, and the correlation between cultivated area and lake changes was extremely low (Figure 6). As the core city of the six central provinces, Wuhan city has rapidly increased its urbanization rate and population. The population in 2019 was about twice that of 1987. The population growth led to a rapid increase in water demand and the rapid development of urbanization led to the emergence of the phenomenon of "building cities around lakes". Agriculture, forestry, animal husbandry and fishery are industries that require huge amounts of water. The increase in the total output value of agriculture, forestry, animal husbandry and fishery will inevitably consume a lot of water resources. Therefore, the lakes in Wuhan were shrinking in general. In addition, large-scale water conservancy projects such as the Three Gorges Dam and the Hanshui South-to-North Water Diversion Project have also caused certain impacts on lake changes. The construction of large-scale water conservancy projects led to a decrease in the groundwater level, and the lack of effective water supply for the lake caused the lake to shrink.

Through the analysis of the correlation, it can be found that the correlation between precipitation and temperature is higher than that of social and economic indicators, but it does not mean that climatic factors are the main driving force of lake changes. On the one hand, society and economic indicators cannot completely replace the impact of human activities on lakes. On the other hand, the Yangtze River and Han River converge in Wuhan, and the impact of these two rivers on the lake has not been quantified. Therefore, it is difficult to judge the main driving force of the lake changes, but it can be concluded that climate factors and human activities together have caused lake changes.
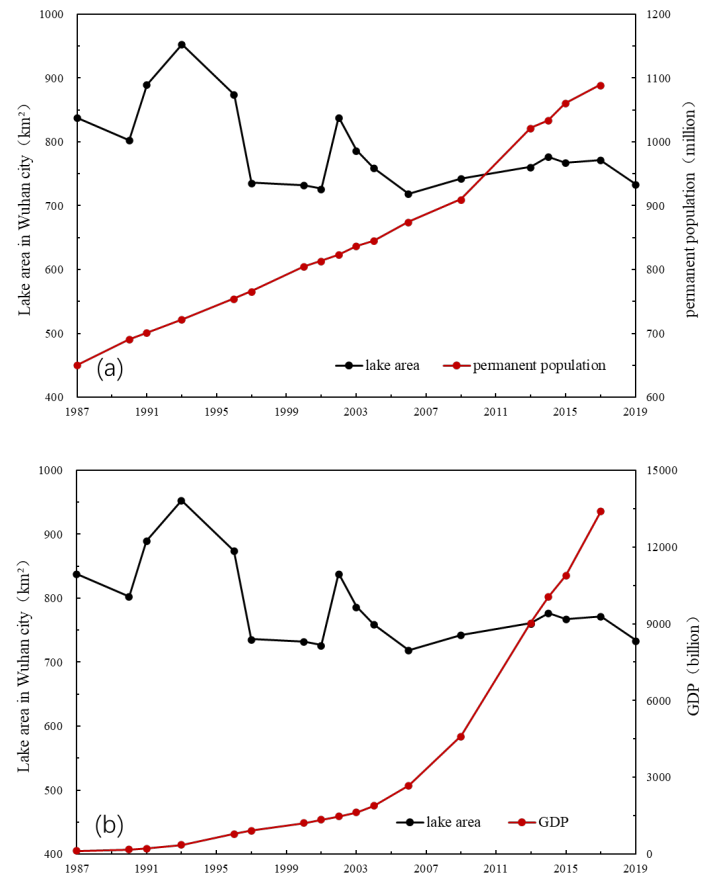

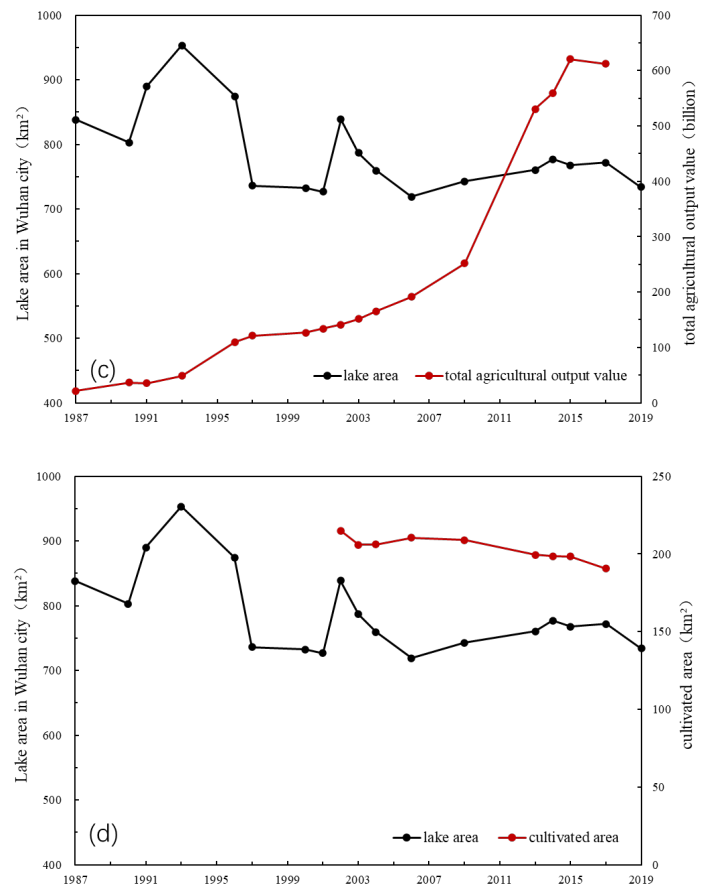

Figure 6. (a) Correlation between permanent population and lake area $(\mathrm{r}=-0.48)$; (b) Correlation between GDP and lake area $(\mathrm{r}=-0.33)$; (c) Correlation between total agricultural output value and lake area $(\mathrm{r}=-0.37)$; (d) Correlation between cultivated area and lake area $(\mathrm{r}=0.15)$.

\section{CONCLUSION}

Lakes are an important city card of Wuhan city, and it is extremely important to study the long-term changes of the lakes since it has great strategic significance for improving the ecological environment and the sustainable development of Wuhan city. We used the MNDWI method and the GEE platform to calculate the lake area from 1987 to 2019 and its change over time and in space, and explore the influencing factors of lake changes. Overall, this study provided the following conclusions: (1) In general, the lakes in Wuhan city were shrinking and the total area decreased from $837.89 \mathrm{~km}^{2}$ in 1987 to $734.10 \mathrm{~km}^{2}$ in 2019 at a rate of $3.15 \mathrm{~km}^{2}$ per year. The changes in lake area were divided into three stages: increasing in the period of 1987 to1993, decreasing in the period of 1993 to 2004 while being stable in the period of 2004 to 2019. (2) Lakes in Wuhan city were mainly distributed in the central and eastern parts of Wuhan city (i.e., Wuchang District, Jiangxia District, and Caidian District). (3) Climate factors and human activities have jointly affected the changes in lake area. (4) The study verified the feasibility of monitoring the long-term lake sequence on the GEE platform, and provided reference for lake protection in Wuhan city. Proactive land planning for urban sustainable development should consider urban lake protecting.

In the future, lake area can be combined with lake levels to estimate lake water volume. The measurement of the lake level includes in-situ measurements and satellite altimetry. Satellite altimetry includes radar altimetry and laser altimetry, and lake level measurement results from satellite altimetry have been shown to help monitor seasonal and inter-annual lake level changes (Song et al., 2014; Wang et al., 2013). Lake water volume is the integral of the relationship between lake area and water level (Duan et al., 2013; Smith et al. 2009). The long-term lake changes will provide a scientific basis for sustainable development of water resources and ecological environment protection in the Wuhan city.

\section{ACKNOWLEDGEMENTS}

This work was supported by the Social Science Foundation of Ministry of Education of China (19YJA840018).

\section{REFERENCES}

Cao, H., Han, L., Liu, Z., Li, L., 2021. Monitoring and driving force analysis of spatial and temporal change of water area of Hongjiannao Lake from 1973 to 2019. Ecological Informatics, 61.

Chen, K., Wang, X., Li, D. Li, Z., 2015. Driving force of the morphological change of the urban lake ecosystem: A case study of Wuhan, 1990-2013. Ecological Modelling, 318(SI), 204-209.

Chen, F., Zhang, M., Tian, B., Li, Z., 2017. Extraction of Glacial Lake Outlines in Tibet Plateau Using Landsat 8 Imagery and Google Earth Engine. IEEE Journal of Selected Topics in Applied Earth Observations and Remote Sensing, 10(9SI), 4002-4009.

Cuffney, T.F., Brightbill, R.A., May, J.T., Waite I.R., 2010. Responses of benthic macroinvertebrates to environmental changes associated with urbanization in nine metropolitan areas. Ecological Application, 20(5), 1384-1401.

Deng, Y., Jiang, W., Tang, Z., Li, J., Lv, J., Chen, Z., Jia, K., 2017. Spatio-temporal change of lake water extent in Wuhan urban agglomeration based on landsat images from 1987 to 2015 . Remote Sensing, 9(3), 270-

Deng, Y., Jiang, W., Tang, Z., Ling, Z., Wu, Z., 2019. Long-term changes of open-surface water bodies in the Yangtze River basin based on the google earth engine cloud platform. Remote Sensing, 11(19), 2213

Du, N., Ottens, H., Sliuzas, R., 2010. Spatial impact of urban expansion on surface water bodies-A case study of Wuhan, China Landscape and Urban Planning, 94(3-4), 175-185.

Duan, Z., Bastiaanssen, W.G.M., 2013. Estimating water volume variations in lakes and reservoirs from four operational satellite altimetry databases and satellite imagery data. Remote Sensing of Environment, 134, 403-416.

Jiang, Z., Jiang, W., Ling, Z., Wang, X., Peng, K., Wang C., 2021. Surface Water Extraction and Dynamic Analysis of Baiyangdian Lake Based on the Google Earth Engine Platform Using Sentinel1 for Reporting SDG 6.6.1 Indicators. Water, 13(2).

Liu, W., Qiu, R., 2007. Water eutrophication in China and the combating strategies. Journal of Chemical Technology, 82(9), 781-786.

Ma, J., Huang, S., Xu, Z., 2017. Satellite remote sensing of lake area in Wuhan from 1973 to 2015. Journal of Hydraulic Engineering, 48, 903-913.

Pekel, J., Cottam, A., Gorelick, N., Belward, A.S., 2016. Highresolution mapping of global surface water and its long-term changes. Nature, 540(7633), 418-. 
Qiao, B., Zhu, L., Yang, R., 2019a. Temporal-spatial differences in lake water storage changes and their links to climate change throughout the Tibetan Plateau. Remote Sensing of Environment, $222,232-243$

Qiao, B., Zhu, L., 2019b. Difference and cause analysis of water storage changes for glacier-fed and non-glacier-fed lakes on the Tibetan Plateau. Science of the Total Environment, 693.

Smith, L.C., Pavelsky, T.M., 2009. Remote sensing of volumetric storage changes in lakes. Earth Surface Processes and Landforms, 34(10), 1353-1358.

Song, C., Huang, B., Richards, K., Ke, L., Vu, H.P., 2014. Accelerated lake expansion on the Tibetan Plateau in the 2000s: Induced by glacial melting or other processes? Water Resources Research, 50(4), 3170-3186.

Song, C., Ye, Q., Cheng, X., 2015. Shifts in water-level variation of Namco in the central Tibetan Plateau from ICESat and CryoSat-2 altimetry and station observations. Science Bulletin, 60(14), 1287-1297.

Tang, L., Duan, X., Kong, F., Zhang, F., Zheng, Y., Li, Z., Mei, Y., Zhao, Y., Hu, S., 2018. Influences of climate change on area variation of Qinghai Lake on Qinghai-Tibetan Plateau since 1980s. Scientific Reports, 8.

Wu, J., Luo, J., Tang, L., 2019. Coupling relationship between urban expansion and lake change- a case study of wuhan. Water, 11(6), 1215

Xie, C., Huang, X., Wang, L., 2018. Spatiotemporal change patterns of urban lakes in China's major cities between 1990 and 2015. International Journal of Digital Earth, 11(11), 1085-1102.

$\mathrm{Xu}, \mathrm{H} ., 2$ 2006. Modification of normalised difference water index (NDWI) to enhance open water features in remotely sensed imagery. International Journal of Remote Sensing, 27(14), 30253033 .

Wang, X., Gong, P., Zhao, Y., Xu, Y., Cheng, X., Niu, Z., Luo, Z., Huang, H., Sun, F., Li, X., 2013. Water-level changes in China's large lakes determined from ICESat/GLAS data. Remote Sensing of Environment, 132, 131-144.

Yasir, M., Sheng, H., Huang, B., Rahman, S.U., 2020. Coastline extraction and land use change analysis using remote sensing (RS) and geographic information system (GIS) technology - A review of the literature. Reviews on Environmental Health, 35, 453-460.

Yang, B., Ke, X., 2015. Analysis on urban lake change during rapid urbanization using a synergistic approach: A case study of Wuhan, China. Physics and Chemistry of the Earth, 89-90: 127135 .

Zhang, B., Wu Y., Zhu L., Wang J., Li J., Chen D., 2011. Estimation and trend detection of water storage at Nam Co Lake, central Tibetan Plateau. Journal of Hydrology, 405(1-2), 161-170

Zhang, G., Yao, T., Xie, H., Zhang, K., Zhu, F., 2014. Lakes' state and abundance across the Tibetan Plateau. Chinese Science Bulletin, 59(24), 3010-3021.

Zhang, Z., Tan, S., Tang, W., 2015. A GIS-based spatial analysis of housing price and road density in proximity to urban lakes in
Wuhan City, China. Chinese Geographical Science, 25(6), 775790 .

Zhou, Y., Dong, J., Xiao, X., Liu, R., Zou, Z., Zhao, G., Ge, Q., 2019. Continuous monitoring of lake dynamics on the Mongolian Plateau using all available Landsat imagery and Google Earth Engine. Science of the Total Environment, 689, 366-380.

Zhang, G., Chen, W., Xie, H., 2019. Tibetan Plateau's Lake Level and Volume Changes from NASA's ICESat/ICESat-2 and Landsat Missions. Geophysical Research Letters, 46(22), 1310713118. 